\title{
Influence of Meteorological Variables on Atmospheric Electric Conductivity over an Urban Location
}

\author{
K. C. Kumar*, K. Nagaraja \\ ASSR Lab, Department of Physics, Bangalore University, Bengaluru - 560056
}

Received 27 January 2020, accepted in final revised form 10 June 2020

\begin{abstract}
The measurements of atmospheric electric conductivity along with selected meteorological parameters was carried out at Bengaluru, an urban site in southern India $\left(12.96^{\circ} \mathrm{N}, 77.56^{\circ}\right.$ E) during January-December 2015 to understand the electric nature of urban air. During the study period, well defined diurnal variation of conductivity was observed with higher values before sun rise and lower values during afternoon hours. For most of the fair weather days, variations in conductivity show a strong correlation with relative humidity and anticorrelation with ambient temperature. The monthly mean values of conductivity show highest values in winter and lowest in monsoon and interestingly a positive Pearson's correlation coefficient of +0.5 was found between measured alpha ionization energy and atmospheric conductivity during the study period.
\end{abstract}

Keywords: Atmospheric electric conductivity; Ion pair production; Atmospheric radioactivity.

(C) 2020 JSR Publications. ISSN: 2070-0237 (Print); 2070-0245 (Online). All rights reserved.

doi: http://dx.doi.org/10.3329/jsr.v12i4.45182

J. Sci. Res. 12 (4), 447-453 (2020)

\section{Introduction}

Since the last eighteenth century, the studies on electric nature of Earth's atmosphere, i.e., ion number density, air earth current, vertical electric field and air conductivity have been continually investigated, due to its relevance with local climate system and the strong connection with global solar terrestrial activities [1-4]. With reference to the altitude, the electric conductivity of air gradually grows from $\sim 10^{-15}$ to $\sim 10^{-10} \mathrm{Sm}^{-1}$, while the vertical electric field decreases from $\sim 10^{2}$ to $\sim 10^{-2} \mathrm{Vm}^{-1}$ from ground level to upper stratosphere. Electric conductivity of the atmosphere, which characterizes its ability to conduct an electric current, is mainly due to cosmic rays, UV radiations and radioactive isotopes [5]. The contribution of cosmic rays and UV radiation is dominant above troposphere and the variation in ionization of air near the ground is mainly due to alpha particles during radioactive decay of ${ }^{222} \mathrm{Rn}$ and its progenies. ${ }^{222} \mathrm{Rn}$ is an inert and naturally occurring radioactive gas with a half-life of 3.823 days (descended of radioactive parent nuclei ${ }^{238} \mathrm{U}$ ) and due to its chemical inertness, the only sink of ${ }^{222} \mathrm{Rn}$ is its decay to daughter nuclei. The principal decay modes and half-lives of radon, its short-lived daughters are ${ }^{222} \mathrm{Rn}-\alpha$,

*orresponding author: dopcharan@gmail.com 
3.823 days; ${ }^{218} \mathrm{Po}-\alpha, 3.05 \mathrm{~min} ;{ }^{214} \mathrm{~Pb}-\beta, 26.8 \mathrm{~min} ;{ }^{214} \mathrm{Bi}-\beta, 19.7 \mathrm{~min}$; and ${ }^{214} \mathrm{Po}-\alpha, 2 \times 10^{-4} \mathrm{~s}$, among which the alpha emitters are main contributors for the ionization of air. The ionization leads to formation of small ions which further interact with different sized aerosols and pollutants [6-8].

The extensive studies have been carried out on ion-aerosol interaction because of their importance in climatic processes. The important motivation for the study of atmospheric electricity parameters, like air earth current, electric field and atmospheric conductivity, is to determine what extent the global electric circuit is a forcing effect on climate [9] and to understand a physical link between solar and geophysical change with the Earth's climate. A feedback of the global circuit-climate interaction exists as increased global surface temperature is expected to cause an increase in convection and therefore global thunderstorm activity. Measurement of the atmospheric electricity parameters may therefore provide insight into global climate change, providing the only method of global climate monitoring to use a single point on the Earth's surface.

It is well established that the atmospheric electrical quantities are sensitive to aerosol, which can provide aerosol ultrafine particle spectrum that no other optimal method can provide. Intergovernmental Panel on Climate Change (IPCC) highlighted that atmospheric aerosols significantly interact with cloud as well as their geographical and vertical distribution (IPCC Working Group I Report, 1995). So if the electrical parameters are known for a site, there is a significant possibility of retrieval of information about aerosol concentration. Hence, measurement of atmospheric electricity may provide a further method of studying global aerosol profiles as well as improving the understanding of aerosol-cloud interactions, as the charge associated with atmospheric electrical processes is expected to modify aerosol-cloud microphysics and affect the formation of clouds $[5,10]$. Hence, a general motivation of this study is to analyse the variations in measured atmospheric electrical parameters with meteorological parameters of climate of single location. Hence, the experimental results of fair-weather atmospheric air conductivity $\left(\sigma_{+}\right)$ with reference to selected meteorological parameters conducted at a metropolitan city Bengaluru $\left(12.96{ }^{\circ} \mathrm{N}, 77.56^{\circ} \mathrm{E}\right)$ during 2015 is presented.

\section{Site Description and Experimental Methodology}

The air conductivity $\left(\sigma_{+}\right)$measurements were carried out at Atmospheric and Space Science Research (ASSR) laboratory located at Jnanabharathi campus of Bangalore University, southern part of India and meteorological parameters was received from two towers installed for micro-meteorological studies near the observatory. The campus is covered with moderate forest area and there is no direct source of air pollution in the immediate vicinity of this location, makes it an ideal place for the measurements of atmospheric electric parameters.

Atmospheric air conductivity was measured using an aspirated Gerdien condenser [11-16], consisting of two identical cylindrical tubes of $10 \mathrm{~cm}$ diameter and $41 \mathrm{~cm}$ length joined by a U-shaped tube. The air was sucked in with a single fan and the shape of Gerdien condenser ensures that the flow of air is laminar, because turbulence flow can 
distort the accuracy of measurement. The inner co-axial electrode in both the tubes is of 1 $\mathrm{cm}$ diameter and $20 \mathrm{~cm}$ length. Opposite but equal potentials of $\pm 35 \mathrm{~V}$ are applied to the outer electrodes of the two condensers. The potential applied to the outer electrode will repel the same polarity ions towards the inner electrode generating an electric pulse in both the pulses. The critical mobility of the instrument is greater than $10^{-4} \mathrm{~m}^{2} \mathrm{~V}^{-1} \mathrm{~S}^{-1}$ and is capable of resolving the values of conductivity as small as $3 \times 10^{-16} \Omega^{-1} \mathrm{~m}^{-1}$. In this paper only positive air conductivity measurements are analyzed along with meteorological parameters. To understand the possible relation of $\sigma_{+}$with atmospheric radioactivity, Genitron made AlphaGUARD PQ 2000 PRO and alpha progeny meter data was simultaneously analyzed. AlphaGUARD PQ-2000PRO is a compact portable measuring system for the continuous monitoring of the radon activity and alpha progeny meter consists of alpha sensitive semiconducting microchip which measures the activity of alpha emitting radon progenies and total alpha ionization energy [16-18].

\section{Results and Discussion}

The atmospheric electric conductivity measurements were conducted during fair weather days i.e., clear sky conditions with no convective activities are considered and presented. The variation of air conductivity with ambient gamma dose levels and selected meteorological parameters i.e., temperature, relative humidity, air pressure are presented in Figs. 1-4. In this study, $\sigma_{+}$has shown a pronounced diurnal variation within a day as reported for south Indian region [19,20].

During the study period it was observed that stability of lower atmosphere strongly influenced the conductivity of lower atmosphere and during fair weather days, a welldefined correlation exists for $\sigma_{+}$with relative humidity and negative correlation with temperature. For example, for a typical day in January 2015, a positive Pearson's correlation coefficient $(r)$ of +0.83 was found between $\sigma_{+}$and relative humidity where $r=$ -0.75 was found between $\sigma_{+}$and temperature [21]. But the value of $r$ is small for $\sigma_{+}$with air pressure and gamma dose rate.

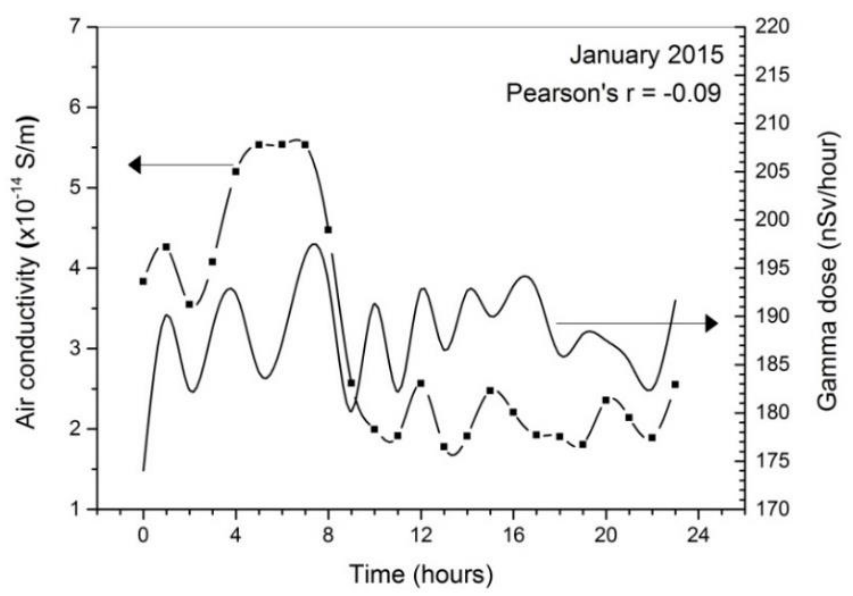

Fig. 1. Variation air conductivity with gamma dose. 


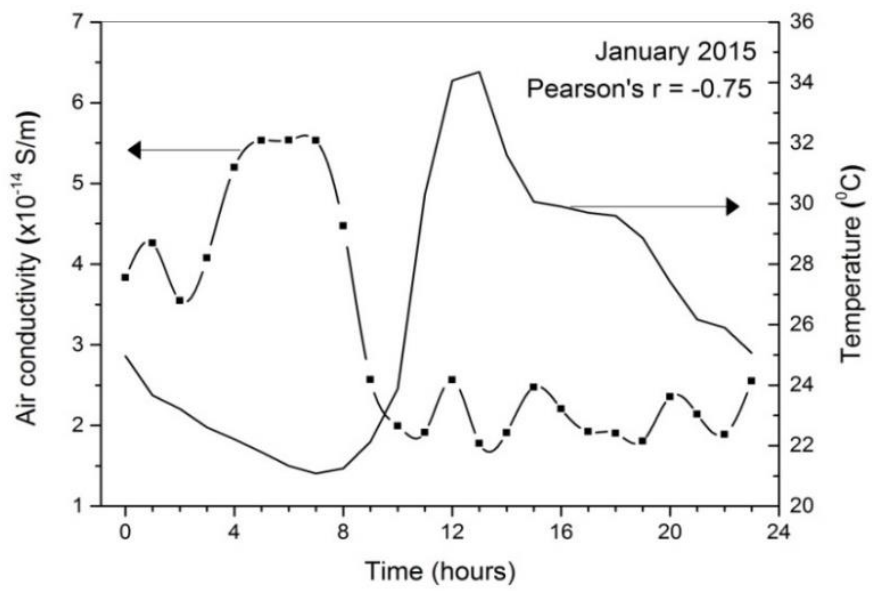

Fig. 2. Variation air conductivity with temperature.

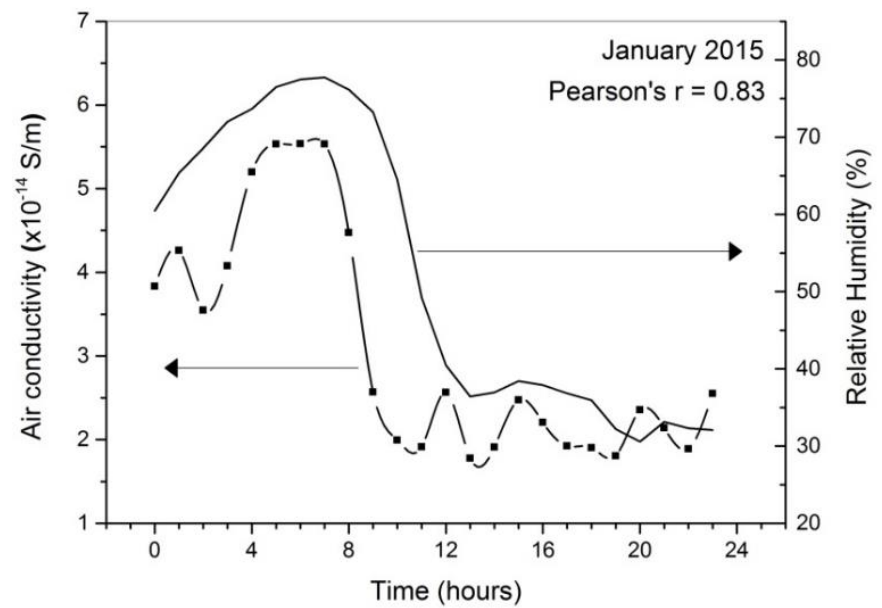

Fig. 3. Variation air conductivity with relative humidity.

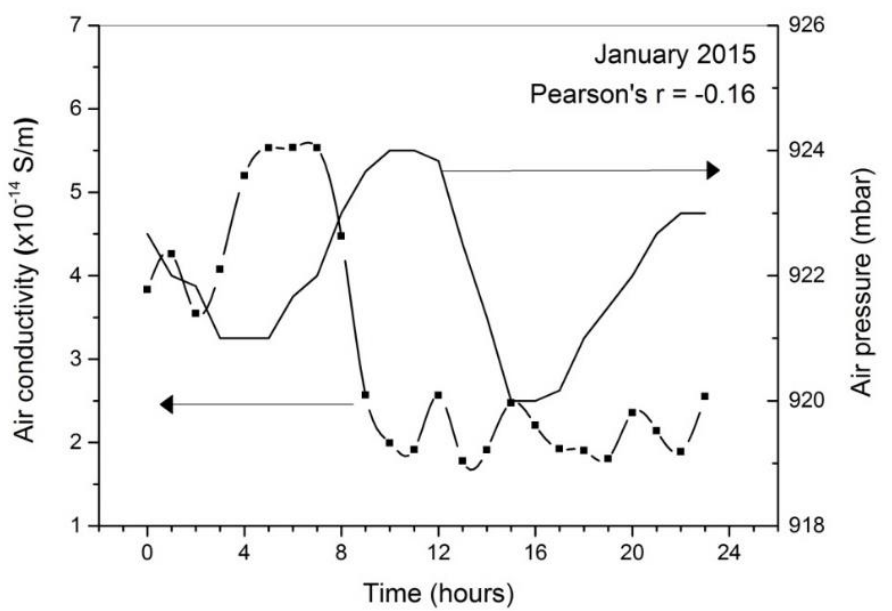

Fig. 4. Variation air conductivity with air pressure. 
It is found that the values of ambient gamma dose were almost constant during observation period. In Fig. 1, relatively small values of $r$ between $\sigma_{+}$and gamma dose indicates that the changes in ionization rate is not due to gamma radiations but may be due to high energy alpha particles from ${ }^{222} \mathrm{Rn}$ and its daughter nuclei.

The evolution of $\mathrm{r}$ for monthly mean values of $\sigma_{+}$with meteorological parameters is presented in Fig. 5. It is observed that, the highest value of $r$ was found during winter months whereas lowest values are observed during monsoon months. This may be attributed to the reduction in $\sigma_{+}$values due to lesser activity of ${ }^{222} \mathrm{Rn}$ and possible precipitation washout of radioactive aerosols during winter season [22-24].

During study period a small campaign was conducted to measure ionization energy from ${ }^{222} \mathrm{Rn}$ and its alpha emitting progenies. The total alpha ionization energy was measured using Genitron made alpha progeny meter [18] and for a typical fair weather day the variation of $\sigma_{+}$with ionization energy is presented in Fig. 6. It is well reported that, small ions generated due to ionization of atmospheric air attached themselves to neutral or charged aerosol/pollutant particles which leads to reduction in air conductivity values [21]. This may be the possible reason for small value of $r=+0.5$ that exists between $\sigma_{+}$and ionization energy. The descriptive statistics of all the measured parameters are presented in Table 1. The measured means follow the trend as reported for south Indian region i.e., January and February, and may be attributed to higher activity of ${ }^{222} \mathrm{Rn}$, whereas lower values were observed during monsoon months [21].

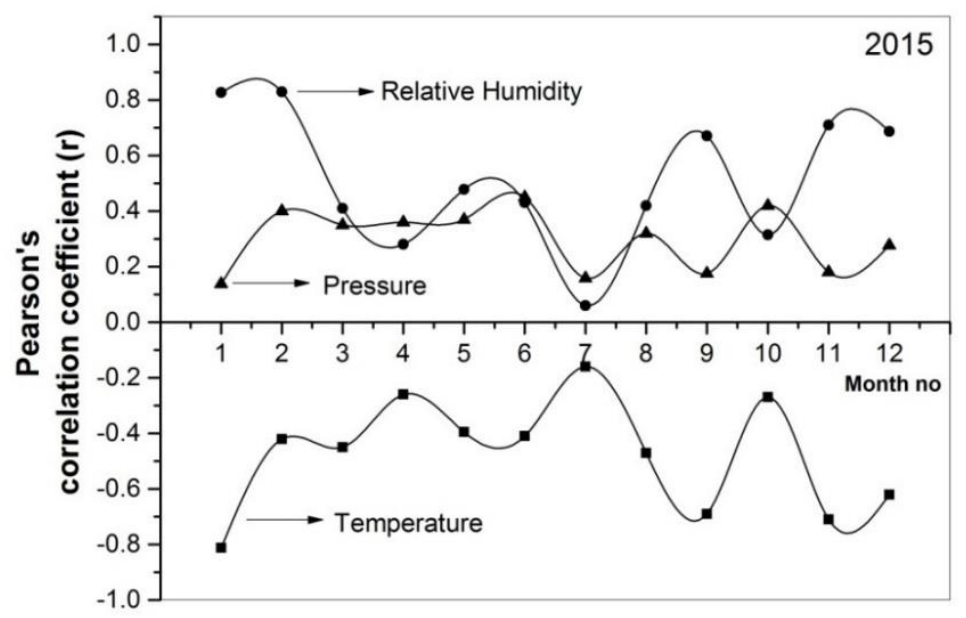

Fig. 5. Evolution of $\mathrm{r}$ values for monthly mean values of $\sigma_{+}$with meteorological parameters. 


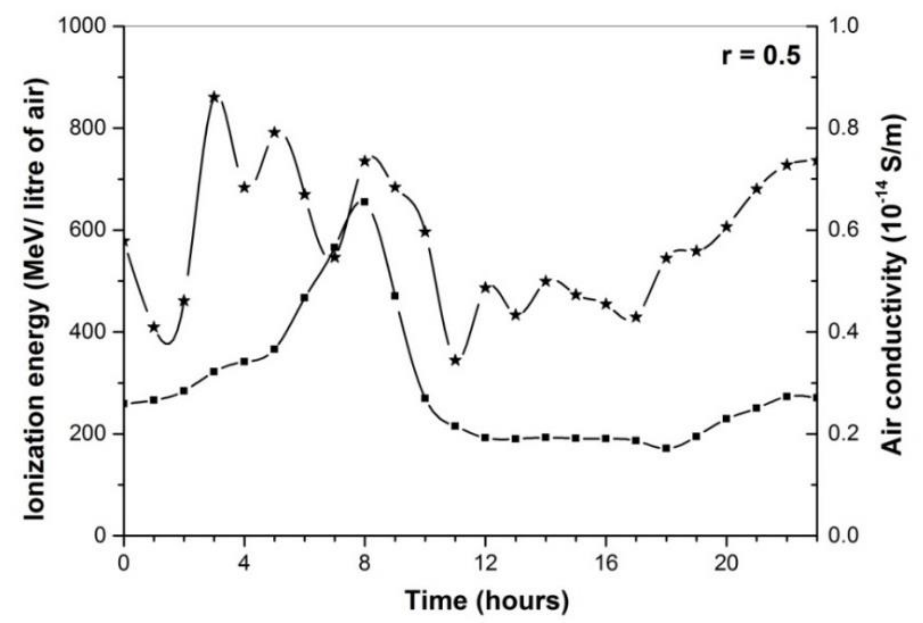

Fig. 6. Variation of $\sigma_{+}$with ionization energy.

Table 1. Descriptive statistics of all the measured parameters.

\begin{tabular}{lcccccc}
\hline 2015 & $\begin{array}{c}\text { Air conductivity } \\
\sigma_{+}\left(10^{-14} \mathrm{~S} / \mathrm{m}\right)\end{array}$ & $\begin{array}{c}\text { Std error } \\
\text { on } \sigma_{+}\end{array}$ & $\begin{array}{c}\text { Temperature } \\
\left({ }^{\circ} \mathrm{C}\right)\end{array}$ & $\begin{array}{c}\text { Relative } \\
\text { humidity }(\%)\end{array}$ & $\begin{array}{c}\text { Air pressure } \\
(\mathrm{mbar})\end{array}$ & $\begin{array}{c}\text { Gamma dose } \\
(\mathrm{nSv} / \mathrm{hour})\end{array}$ \\
\hline January & 2.79 & 0.09 & 25.48 & 58.75 & 920.80 & 188.42 \\
February & 3.01 & 0.22 & 30.16 & 47.74 & 918.27 & 222.34 \\
March & 1.30 & 0.03 & 29.40 & 52.49 & 921.12 & 225.97 \\
April & 1.21 & 0.04 & 28.68 & 58.72 & 918.56 & 190.25 \\
May & 0.70 & 0.04 & 26.84 & 66.76 & 917.31 & 190.55 \\
June & 0.79 & 0.06 & 26.18 & 76.33 & 916.31 & ------ \\
July & 0.38 & 0.00 & 26.41 & 72.82 & 917.19 & 191.16 \\
August & 0.59 & 0.03 & 26.24 & 75.76 & 917.58 & 191.62 \\
September & 0.69 & 0.04 & 26.50 & 75.62 & 918.16 & 191.40 \\
October & 0.91 & 0.06 & 27.42 & 71.21 & 920.06 & 190.56 \\
November & 0.90 & 0.05 & 25.42 & 75.40 & 919.64 & 191.65 \\
December & 1.47 & 0.06 & 25.74 & 71.87 & 920.53 & 191.89 \\
Average & $\mathbf{1 . 2 3}$ & $\mathbf{- - - - -}$ & $\mathbf{2 7 . 0 4}$ & $\mathbf{6 6 . 9 6}$ & $\mathbf{9 1 8 . 8 0}$ & $\mathbf{1 9 6 . 8 9}$ \\
\hline
\end{tabular}

\section{Conclusion}

To study the electric nature of urban air, one year data set of air conductivity (positive, $\sigma_{+}$) measurements along with meteorological parameters was analyzed. It was observed that both temperature and relative humidity has strong correlation with atmospheric conductivity $\left(\sigma_{+}\right)$and a positive Pearson's correlation coefficient (r) of +0.5 was found between measured alpha ionization energy and air conductivity. The mean values of $\sigma_{+}$ show significant monthly variations with maximum in winter months and minimum during monsoon months as reported earlier for the similar environments.

\section{Acknowledgment}

Authors would like to thank Indian Space Research Organization for providing financial support through RESPOND project. 


\section{References}

1. V. M. Sheftel, A. K. Chernyshev, and P. Chernysheva, J. Geophys. Res. 99, 10793 (1994). https://doi.org/10.1029/94JD00287

2. G. K. Manohar, S. S. Kandalgaonkar, and M. K. Kulkarni, J. Geophys. Res. 100, 20805 (1995). https://doi.org/10.1029/95JD01295

3. R. G. Harrison and K. S. Carslaw, Rev. Geophys. 41, 1 (2003). https://doi.org/10.1029/2002RG000114

4. D. Retalis, A. Pitta, and P. Psallidas, Meteorol. Atmos. Phys. 46, 197 (1991). https://doi.org/10.1016/j.atmosres.2008.05.011

5. E. Seran, M. Godefroy, E. Pili, N. Michielsen, and S. Bondiguel, Earth Space. Sci. 4.2, 91 (2017). https://doi.org/10.1002/2016EA000241

6. N. Srinivas, B. S. N Prasad, and K. Nagaraja, Ind. J. Radio. Space. Phys. 30, 31 (2001). https://doi.org/10.1016/j.jastp.2005.12.005

7. N. Kamsali, B. S. N. Prasad, and J. Datta, Adv. Space. Res. 44, 1067 (2009). https://doi.org/10.1016/j.asr.2009.05.020

8. A. Boldyreff, G. Kupovykh, and A. Redin, J. Electrostat. 71, 305 (2013). https://doi.org/10.1016/j.elstat.2013.01.004

9. G. B. Burns, A.V. Frank-Kamenetsky, B. A. Tinsley, W. J. R. French, P. Grigioni, G. Camporeale, and E. A. Bering, J. Atmos. Sci. 74, 783 (2017). https://doi.org/10.1175/JAS-D-16-0159.1

10. S. D. Pawar, V. Gopalakrishnan, P. Murugavel, N. E. Veremey, and A. A. Sinkevich, Atmos. Res. 183, 331 (2016). https://doi.org/10.1016/j.atmosres.2016.09.016

11. G. B. Patil, S. D. Pawar, and J. L. Bhosale, J. Phys.: Conf. Ser. 1172, 1 (2019). https://doi.org/10.1088/1742-6596/1172/1/012010

12. S. Dhanorkar, C. G. Deshpande, and A. K. Kamra, Atmos. Environ. 23, 839 (1989). https://doi.org/10.1016/0004-6981(89)90488-5

13. K. L. Aplin and R. G. Harrison, Rev. Sci. Instrum. 71, 8 (2000). https://doi.org/10.1063/1.1305511

14. K. L. Aplin, Rev. Sci. Instrum. 76, 104501 (2005). https://doi.org/10.1063/1.2069744

15. P. Kolarž, B. P. Marinković, and D. M. Filipović, Rev. Sci. Instrum. 76, 46107 (2005). https://doi.org/10.1063/1.1891444

16. K. Nagaraja,, B. S. N. Prasad, N. Srinivas, and M. S. Madhava, J. Atmos. Sol. Terr. Phys. 68, 757 (2006). https://doi.org/10.1016/j.jastp.2005.12.005

17. M. Zoran, M. R. Dida, R. Savastru, D. Savastru, and A. Dida, O. Ionescu, J. Radioanal. Nucl. Chem. 300, 729 (2014). https://doi.org/10.1007/s10967-014-3041-1

18. M. Zimnoch, P. Wach, L. Chmura, Z. Gorczyca, K. Rozanski, and J. Godlowska, Atmos. Chem. Phys. 14, 9567 (2014). https://doi.org/10.5194/acp-14-9567-2014

19. K. C. Kumar, T. R. Prasad, T. N. Rao, M. Venkataratnam, and K. Nagaraja, Int. J. Radiat. Res. 14, 2 (2016). https://doi.org/10.18869/acadpub.ijrr.14.2.105

20. J. A. Chalmers, Atmospheric Electricity, (Pergamon Press, London, 1976) vol. 11, pp. 1.

21. M. S. Chandrashekara, J. Sannappa, and L. Paramesh, Atmos. Environ. 40, 1 (2006). https://doi.org/10.1016/j.atmosenv.2005.09.026

22. B. S. N. Prasad, K. Nagaraja, M. S. Chandrashekara, L. Paramesh, and M.S. Madhava, Atmos. Res. 76, 65 (2005). https://doi.org/10.1016/j.atmosres.2004.11.011

23. A. Kumar, Indian J. Phys. 87, 411 (2013). https://doi.org/10.1007/s12648-013-0250-3

24. V. Sasikumar, S. Sampath, S. Muralidas, and K. Vijaykumar, Geophys. J. Int. 122, 89 (1995). https://doi.org/10.1111/j.1365-246X.1995.tb03538.x 